\title{
A Patient With Coinheritance of Alpha-Globin Gene Triplication and IVSI-5 Mutation of Beta-Globin Gene
}

\author{
Majid Naderi ${ }^{1, *}$; Ibrahim Miri-Moghaddam ${ }^{1}$; Akbar Dorgalaleh ${ }^{2}$; Shaban Alizadeh ${ }^{2}$; Shadi \\ Tabibian $^{2}$; Masoud Pishjoo ${ }^{3}$ \\ ${ }_{\text {G }}^{1}$ Genetic Researcher Center in Non Communicable Disease, Zahedan University of Medical Sciences, Zahedan, IR Iran \\ ${ }_{3}^{2}$ Department of Hematology, Allied Medical School, Tehran University of Medical Sciences, Tehran, IR Iran \\ 3 Medical Student Research Center, Zahedan University of Medical Sciences, Zahedan, IR Iran \\ ${ }^{*}$ Corresponding author: Majid Naderi, Genetic Researcher Center in Non-Communicable Disease, Zahedan University of Medical Sciences, Zahedan, IR Iran, Iran. \\ E-mail: majid_naderi2000@yahoo.com \\ Received: April 11, 2014; Accepted: June 24, 2014
}

\begin{abstract}
The $-\alpha 3.7$ rightward deletion is the most frequent $\alpha$-globin mutation but $\alpha \alpha \alpha$ (anti 3.7) triplication is relatively rare. We describe 2 years old female that was heterozygous of IVSI-5 mutation and homozygous $\alpha 3.7$ triplication. The hematological picture of $\beta$-thalassemia heterozygotes with a triplicated $\alpha$-globin gene arrangement is variable. Suggested that homozygous alpha-gene triplication interacts with a severe $\beta$-thalassemia mutation to cause $\alpha$-chain excess equivalent to that observed in homozygous $\beta$-thalassemia intermedia.
\end{abstract}

Keywords: Thalassemia Intermedia; Alpha 3.7 Triplication; $\beta$-Thalassemia

\section{Introduction}

The $-\alpha 3.7$ rightward deletion is the most frequent $\alpha$-globin deletion worldwide, while frequency of the $\alpha \alpha \alpha$ anti 3.7 triplication are not clearly determined. Carriers of the $\alpha \alpha \alpha$ anti 3.7 triplication show no clinical symptoms or significant hematological changes, but it co-existence with $\beta$-thalassemia ( $\beta$-thal) worsen the clinical and hematological features of the patient as well as the trait $[1,2]$.

Thalassemia intermediate is referred to a group of disorders with a less severe form of the disease when compared with thalassemia major. Patients with thalassemia intermedia may present with diverse pathology but the most accepted definition is that, a patient may start to become transfusion-dependent later in life, usually after age of 3 years. They are either transfusion independent or require transfusion at longer intervals than monthly. Basically clinical severity of the disease in the patient is associated with the degree of $\alpha /$ non- $\alpha$ chain imbalance. This phenotype may be caused by co-existence of one $\beta$-globin gene defect along with an excessive $\alpha$-globin gene expression due to alpha triplication. Here we describe a child with thalassemia intermedia phenotype due to homozygote alpha triplication ( $\alpha \alpha \alpha$ anti 3.7/ $\alpha \alpha \alpha$ anti 3.7) and a $\beta$-globin gene mutation (IVSI-5) [2-5].

\section{Case Presentation}

A 2-year-old Iranian infant with jaundice referred to the pediatric physician. The patient had thalassemia facies with prominent diploes, splenomegaly and failure to thrive in physical exam. In workup is taken from the patient's $\mathrm{CBC}$ test that results as seen below: $\mathrm{RBC}$ Count $=3.45 \times 10^{6} / \mu \mathrm{L}, \mathrm{Hb}=6.5 \mathrm{mg} / \mathrm{dL}, \mathrm{HCT}=23.2 \%, \mathrm{MCV}=67.2 \mathrm{fL}$, $\mathrm{MCH}=18.8 \mathrm{pg}, \mathrm{MCHC}=28 \mathrm{~g} / \mathrm{dL}, \mathrm{RDW}=27.8$.

In the peripheral blood smear was have seen hypochromic and microcytic RBC's with Target cell, tear drop, schistocyte and 5 to 100 NRBC per each 100 WBC.

The results of patient's iron profile following serum iron $=63$, TIBC $=449$ was normal. The above results for the presumptive diagnosis of thalassemia patients were given. Therefore the test for hemoglobin electrophoresis was done that result as seen below: $\mathrm{HbA} 1=75 \%, \mathrm{HbA} 2=$ $4.2 \%, \mathrm{HbF}=20.7 \%$.

Also in this case, the G6PD enzyme activity was abnormal. According to this matter that patient parents were relative couple, CBC test for the patient's parents requested that the results can be seen in Table 1 . Therefor the patient diagnosed with thalassemia intermedia and G6PD deficiency. For patient transfused 5 unit of packed RBC. After 4 month of the last transfusion suggest molecular studies for patient. In molecular studies of beta-thalassemia carriers, according to the patient's father has heterozygous mutation of IVSI-5 with heterozygous of $\alpha 3.7$ triplication.

The patient's mother also suffered heterozygous $\alpha 3.7$ triplication. Also patients has heterozygous mutations of IVSI-5 and homozygous $\alpha 3.7$ triplication in the next pregnancy of mother's patient, mother evaluated for prenatal diagnosis. With chorionic villous sampling, became clear that the fetus is homozygous of $\alpha 3.7$ triplication. After her sister had born, she had similar symptoms like hers.

Copyright (C) 2015, Zahedan University of Medical Sciences. This is an open-access article distributed under the terms of the Creative Commons Attribution-NonCommercial 4.0 International License (http://creativecommons.org/licenses/by-nc/4.0/) which permits copy and redistribute the material just in noncommercial usages, provided the original work is properly cited. 
Table 1. RBC Indices and Hemoglobin Electrophoresis of Patient and her Family

\begin{tabular}{lcccc}
\hline & Patient & Father & Mother & Sister \\
\hline RBC, $\mathbf{m i l} / \mu \mathbf{L}$ & 3.45 & 5.57 & 4.49 & 3.88 \\
\hline Hb, g/dL & 6.5 & 11.6 & 14.1 & 3.88 \\
\hline HCT, \% & 23.2 & 38.5 & 41.6 & 23.6 \\
\hline MCV, fL & 67.2 & 69.8 & 92.7 & 60.8 \\
\hline MCH, pg & 18.8 & 20.8 & 31.4 & 17.5 \\
\hline MCHC, g/dL & 28 & 29.8 & 33.9 & 28.8 \\
\hline RDW, \% & 27.8 & 16.8 & 11.9 & 28.8 \\
\hline HbA1, \% & 75 & 95.6 & 96 & 95.3 \\
\hline HbA2, \% & 4.2 & 3.9 & 2.9 & 4.2 \\
\hline HbF, \% & 20.7 & 0.5 & 0.1 & 0.5 \\
\hline
\end{tabular}

\section{Discussion}

The present of extra $\alpha$-globin gene lead to Surplus production of $\alpha$-globin chains that is particularly important in case of $\beta$-thalassemia and can cause severe anemia with significant clinical manifestation. The degree of anemia and severity of clinical presentation depend on the number of extra copies of $\alpha$-genes and kind of $\beta$-globin mutation. Basically in $\beta$-thalassemia, it is excess alpha chains that induce hemolysis in erythroid precursors and cause severe anemia with significant clinical phenotype $[1,2]$. Although in $\beta$-thalassemia minor the $\alpha /$ non- $\alpha$-chain imbalance is slight and just cause mild anemia without clinical symptoms but its co-inheritance with $\alpha$-thalassemia has been reported to modified the clinical features of the disease [3]. Rarely alpha gene numerical alteration can occurred that in combination with $\beta$-thalassemia minor exacerbate clinical and hematological phenotype of the disease. Alpha gene triplication ( $\alpha \alpha \alpha$ anti 3.7) is a extremely rare numerical change of alpha gene that in co-existence with $\beta$-thalassemia minor worsen the phenotype of $\beta$-thalassemia minor and make differential phenotypes. Co-inheritance of heterozygous $\beta$-thalassemia and homozygous $\alpha 3.7$ triplication generally cause thalassemia intermediate phenotype [4].

Since $\beta$-thalassemia is one of the most common monogenic disorders in the Iran such other parts of the world and its frequency close to $10 \%$ in some southern parts of Iran (including Sistan and Balouhestan) and moreover $-\alpha 3.7$ allele is the most frequent $\alpha$-globin mutation, it seems that co-inheritance of anti 3.7 triplication with $\beta$-thalassemia frequently occurred in general population of the country and adverse clinical manifestation of $\beta$-thalassemia [2].

Galanello et al. in 1983 described a Sardinian family with coinheritance of $\beta$-thalassemia and triplicated $\alpha$-globin gene loci and different genotype and phenotypes. They concluded that heterozygote for triple $\alpha$-loci showed no clinical manifestations and the homozygous state for the triplicated $\alpha$-globin gene loci, expresses no hemato- logic manifestations. The coexistence of heterozygous $\beta$-thalassemia with the heterozygous state for the triple $\alpha$-globin loci produces no clinical manifestations and is associated with a hematologic phenotype like heterozygous $\beta$-thalassemia. But combination of the homozygous of triplicated $\alpha$-globin gene loci and the heterozygous state for $\beta$-thalassemia produced a clinical picture of thalassemia intermedia with mild clinical course [4]. Traeger-Synodinos et al. in a study described 3 patients with combination of $\beta$-thalassemia heterozygotes and homozygosis for $\alpha$-globin gene triplication. All patients had intermediate phenotype and 2 of them had mild hepatosplenomegaly but no bone changes. They also describe 17 patients ( 6 children and 11 adults) with heterozygous $\beta$-thalassemia and heterozygosity for a triple-globin gene. Most of the patients had mild to moderate anemia with no different between hematological findings in children and adults [5].

Kimura et al. reported a 6-year-old Caucasian Brazilian boy with moderately severe chronic anemia with microcytic hypochromic cells and splenomegaly. Investigation of the $\alpha$-globin and $\beta$-globin genes revealed heterozygosis of this patients for both $\beta$-IVS-II- $1(\mathrm{G} \rightarrow \mathrm{A})$ mutation and $\alpha \alpha \alpha a n t i-3.7$ allele that led to thalassemia intermediate [6].

Also in a case that reported by Constanco et al., a 19 years old woman with chronic mild anemia, jaundice and splenomegaly was heterozygote for both the mutation Beta IVSI- $110 \mathrm{G}>\mathrm{A}$ and the $\alpha \alpha \alpha$ anti 3,7 allele. This case brings again to discussion the complexity of genetic interactions underlying a phenotype of thalassemia intermedia [7]. In a study that was done by Camaschella et al. on 17 patients with heterozygous of $\alpha \alpha \alpha a n t i-3.7$ allele and a mutation in the $\beta$-globin gene cluster it was cleared that 11 patients in spite of this genotype had severe anemia with requirement to splenectomy and transfusion in some cases [8]. These studies showed that coinheritance of heterozygous triplicated $\alpha$-gene with heterozygous $\beta$-thalassemia can led to diverse clinical phenotypes. It is likely that other factors influenced balance between $\alpha$-and $\beta$-chains and therefore clinical manifestations of disorder.

\section{Authors' Contributions}

All authors had equal role in design, work, statistical analysis and manuscript writing.

\section{Funding/Support}

Zahedan University of Medical Sciences.

\section{References}

1. Moosavi SF, Amirian A, Zarbakhsh B, Kordafshari A, Mirzahosein $\mathrm{H}$, Zeinali S, et al. The carrier frequency of alpha-globin gene triplication in an Iranian population with normal or borderline hematological parameters. Hemoglobin. 2011;35(4):323-30.

2. Fallah MS, Zadeh-Vakili A, Aleyasin SA, Mahdian R, Karimipour M, Raeisi M, et al. Molecular characterization of thalassemia intermedia, due to co-inheritance of homozygous alpha triplication and IVSI-5 beta-thalassemia. Blood Cells Mol Dis. 2009;43(2):158-60. 


\section{Naderi M et al.}

3. Bragos IM, Noguera NI, Raviola MP, Milani AC. Triplication(/alphaalphaalpha anti3.7) or deletion (-alpha3.7/) association in Argentinian beta-thalassemic carriers. Ann Hematol. 2003;82(11):696-8.

4. Galanello R, Ruggeri R, Paglietti E, Addis M, Melis MA, Cao A. A family with segregating triplicated alpha globin loci and beta thalassemia. Blood.1983;62(5):1035-40.

5. Traeger-Synodinos J, Kanavakis E, Vrettou C, Maragoudaki E, Michael T, Metaxotou-Mavromati A, et al. The triplicated alphaglobin gene locus in beta-thalassaemia heterozygotes: clinical, haematological, biosynthetic and molecular studies. BrJ Haematol.1996;95(3):467-71.
6. Kimura EM, Grignoli CR, Pinheiro VR, Costa FF, Sonati MF. Thalassemia intermedia as a result of heterozygosis for beta 0 -thalassemia and alpha alpha alpha anti-3,7 genotype in a Brazilian patient. Braz J Med Biol Res. 2003;36(6):699-701.

7. Constanco MC, Rocha P, Bento C, Silva HM. [Heterozygous beta thalassemia with triplication of the alpha globin gene]. Portuguese. Acta Med Port. 2011;24(4):633-6.

8. Camaschella C, Kattamis AC, Petroni D, Roetto A, Sivera P, Sbaiz $\mathrm{L}$, et al. Different hematological phenotypes caused by the interaction of triplicated alpha-globin genes and heterozygous betathalassemia. Am J Hematol. 1997;55(2):83-8. 